\title{
Taking phenomenology beyond the first-person perspective: conceptual grounding in the collection and analysis of observational evidence
}

\author{
Marianne Elisabeth Klinke ${ }^{1,2}$ (D) Anthony Vincent Fernandez $z^{3,4}$ (D)
}

Accepted: 8 December 2021/Published online: 9 January 2022

(C) The Author(s) 2021, corrected publication 2022

\begin{abstract}
Phenomenology has been adapted for use in qualitative health research, where it's often used as a method for conducting interviews and analyzing interview data. But how can phenomenologists study subjects who cannot accurately reflect upon or report their own experiences, for instance, because of a psychiatric or neurological disorder? For conditions like these, qualitative researchers may gain more insight by conducting observational studies in lieu of, or in conjunction with, interviews. In this article, we introduce a phenomenological approach to conducting this kind of observational research. The approach relies on conceptual grounding to focus a study on specific aspects of the participants' experiences. Moreover, the approach maintains the openness to novel discoveries that qualitative research requires while also providing a structured framework for data collection and analysis. To illustrate its practical application, we use examples of hemispatial neglect-a neurologic disorder in which patients characteristically lack awareness of their own illness and bodily capacities. However, the approach that we describe can be applied more broadly to the study of complex illness experiences and other experiential alterations.
\end{abstract}

Keywords Phenomenology · Observational research · Qualitative methods · Embodiment $\cdot$ Hemispatial neglect

Marianne Elisabeth Klinke

marianne@hi.is

Anthony Vincent Fernandez

AFernandez@health.sdu.dk

1 Faculty of Nursing, School of Health Sciences, University of Iceland Eirberg, Eiriksgata 34, 107 Reykjavik, Iceland

2 The National University Hospital of Iceland, Reykjavik, Iceland

3 Faculty of Philosophy, University of Oxford, Oxford, UK

4 Danish Institute for Advanced Study and Department of Sports Science and Clinical Biomechanics, University of Southern Denmark, Odense, Denmark 


\section{Introduction}

Phenomenology, originally established as a philosophical research program, has been adapted for use across a variety of scientific disciplines, such as psychology, psychiatry, sociology, anthropology, and nursing. In each case, the adaptation requires the development of new ways of integrating phenomenology with the aims of the scientific field. In qualitative research in psychology and health care, for instance, there's an extensive literature on how phenomenology may be used to conduct interviews and analyze interview data. However, in these fields, there's relatively little methodological literature on the use of phenomenology in observational research, despite phenomenology's influence on observational studies in sociology and anthropology, among other fields.

In this article, we introduce a phenomenological approach to conducting observational research that uses conceptual grounding to focus the study on specific aspects of the participants' experiences. We argue that phenomenological interviewing is not, on its own, an adequate approach for studying certain subjects, including those who cannot accurately report or describe their own experiences. We demonstrate how phenomenologists can use observational evidence of human behavior in conjunction with first-person, self-reflective evidence. And we outline an approach to collecting and analyzing such evidence by using conceptual grounding. This approach is designed primarily for in-depth studies of first-person experiential alterations that are often difficult to understand or describe, such as in cases of complex illness experience. In this respect, it differs from anthropological approaches to integrating ethnography with phenomenological theory, which are often used to study social or cultural practices. Drawing on our own academic backgrounds in phenomenological psychiatry and neurological nursing, we illustrate our approach with an example of hemispatial neglect following stroke-in the following, referred to simply as "neglect" - which is a paradigmatic case of a condition that thwarts traditional techniques for understanding others' experiences. However, the approach that we develop here may also be used to study other experiential alterations, including in cases where subjects are capable of accurately reflecting upon and describing their own experiences.

The article proceeds in 6 parts. First, we argue that an exclusive reliance on interviews is not sufficient to understand certain complex illness experiences and we therefore provide a philosophical justification for using behavioral evidence in applied phenomenology. Second, we identify some of the challenges of conducting observational research from a phenomenological perspective and outline how we aim to address these challenges. Third, we introduce an approach that uses conceptual grounding to collect observational evidence, which can supplement the shortcomings of first-person, self-reflective evidence. Fourth, we present a case study of a patient with neglect to illustrate the main characteristics of the disorder and highlight concrete problems that confront the researcher when accessing "neglect" experiences. Fifth, we outline different modes of observations that the phenomenologist can use and briefly describe how these modes of observation can help us understand complex experiences like neglect. Sixth, we use an empirical study of neglect to 
illustrate how our method of combining self-reflective evidence with observations can be employed and how researchers can use phenomenological concepts to navigate data collection and analysis when investigating complex illness experiences and other cases of experiential alteration.

\section{Phenomenology and behavioral evidence: a philosophical justification}

Without an adequate grasp of patients' experiences, it's difficult to provide quality care. For this reason, qualitative health researchers draw extensively on phenomenological approaches to interviewing and data analysis (see, e.g., Englander, 2012, 2020; Giorgi, 2009; Høffding \& Martiny, 2016; Smith et al., 2009; van Manen, 1990, van Manen, 2016). Interviews are a valuable tool for gaining insight into illness experience, especially the experiences of people living with somatic conditions. However, approaches that rely exclusively on interview data face fundamental limitations when used to study the experience of people living with psychiatric or neurological conditions, some of which involve impaired insight or impaired capacities for verbal or written expression. If an interviewee is unable to accurately reflect upon their own experience or express or describe their experience, then the interviewer-no matter how skilled-cannot gain an adequate grasp of the experience.

Louis Sass and Elizabeth Pienkos acknowledge this problem when they write,

One limitation of our study, as with all phenomenological research, is that we must rely largely on patients who are able to describe their experiences; this can involve a selection bias in favour of patients who may not be typical of the entire diagnostic group at issue. Although this issue must be borne in mind, it must also be recognized that this is a necessary feature of phenomenological work, one that can only be avoided at the risk of ignoring the subtle features of a patient's subjectivity. (Sass \& Pienkos, 2013, 108)

Sass and Pienkos' characterization is representative of how many phenomenologists conceive of the discipline and its limitations, although few researchers have articulated this problem so directly. But do conditions that compromise the ability to describe one's experience stand on the very edge, or even beyond, the domain of phenomenological research? Is this an inescapable limitation of phenomenology? We argue that, in contrast with popular characterizations of phenomenological methodology, phenomenologists do not rely exclusively on first-person, selfreflective evidence. When we say this, however, we don't have in mind approaches like Francisco Varela's neurophenomenology, where phenomenological accounts of experience and neuroscientific accounts of the brain impose mutual constraints upon each other (Varela, 1996; Varela and Shear, 1999). This kind of cross-disciplinary dialogue is valuable for phenomenological research, but doesn't challenge phenomenology's first-person, self-reflective methodology. In our proposal, by contrast, we argue that phenomenologists can collect and analyze behavioral evidence in much the same way that they do for self-reflective experiential evidence. 
At first, this may seem like a radical departure from what many of us take phenomenology to be. In philosophy, phenomenology is popularly characterized as "the study of structures of consciousness as experienced from the first-person point of view" (Smith, 2018). This characterization is not, however, aligned with the classical texts. Many phenomenologists made claims about experience that were not supported by first-person, self-reflective evidence. Husserl and Heidegger, for example, made phenomenological claims about the experiences of non-human animals. Merleau-Ponty also developed detailed studies of infant experience. And, in his studies of subjects with neurological or psychiatric conditions, he often relied more heavily on descriptions of their behavior provided by neurologists and psychologists than he did on their own self-reports. If we turn to more contemporary studies, such as Shaun Gallagher's analysis of the case of Ian Waterman, we find a similar reliance on observations of Waterman's behavior used in conjunction with his first-person reports (Gallagher, 2005). ${ }^{1}$

In much of the classical literature, this use of observational or behavioral evidence remains unacknowledged. One exception, however, is Merleau-Ponty's discussion of behavioral evidence in his lectures on phenomenology and the human sciences. Reflecting on the classical foundations of phenomenological methodology, he says,

Husserl was so far from making internal perception into a principle that he granted a greater certitude, in certain respects, to external perception than to internal observation. Reflection on the meaning or the essence of what we live through is neutral to the distinction between internal and external experience. (Merleau-Ponty, 1964, 64-65; emphasis in original)

The internal-external distinction that Merleau-Ponty uses here is not especially common in phenomenology. But his elaboration suggests that "external perception" refers to the observation of another's behavior. He says,

...nothing prevents my phenomenological reflection from having a bearing [...] on another person, since I perceive him and his modes of behavior. Nothing prevents the clarification of the intentions or meanings or ways of acting from referring not only to my own conduct but to that of another whom I witness. Nothing prevents me from explaining the meaning of the lived experience of another person, in so far as I have access to it, by perception. (Merleau-Ponty, 1964, 65)

Here, Merleau-Ponty broadens the scope of phenomenological reflection to include the researcher's ability to reflect on others' behavior. Between his own studies of people with psychiatric and neurological disorders and these methodological

\footnotetext{
1 For further readings of the case of Ian Waterman, we refer to the book Pride and a Daily Marathon where the neurologist Jonathan Cole provides in-depth insight into how Waterman developed strategies to move around and manage many common daily activities although he, due to a rare auto-immune neurological condition, lost all sense of position and proprioception below the neck when he was 19 years old (Cole, 1995).
} 
remarks, we have precedent for the use of behavioral evidence in phenomenology. But this leaves us with two key questions: First, how should phenomenologists justify the use of behavioral evidence? Second, how should phenomenologists collect and analyze behavioral evidence?

To the first question, there may be various ways to justify the use of behavioral evidence in phenomenological research. However, because we aim to outline concrete methods for collecting and analyzing such evidence, we'll provide just one brief justification: Within phenomenology, human behavior isn't studied as the effect of physiological or neurological processes. Rather, behavior is understood as expressive. Bodily actions can express subjective states, such as beliefs, desires, emotions, and intentions. And they can also express the sense or meaning of objects within another's lived world. If you see your friend tense her muscles and stand erect as a dog runs toward her, you perceive not only her subjective feeling of fear, but also the dog as a fearsome object within her lived world-even if it doesn't have this sense within your lived world. Just as you understand the other's experience through verbal expressions, you can understand the other's experience through bodily expressions. This is why the phenomenological use of behavioral evidence differs fundamentally from the phenomenological use of neurological evidence. Behavioral evidence, like first-person self-reflective evidence, directly expresses subjectivity.

The second question, regarding how we should collect and analyze this evidence, is more difficult to answer. The classical phenomenologists provide remarkably little in the way of concrete methodological advice. To develop an approach to collecting and analyzing behavioral evidence in phenomenological studies, we need to look to contemporary approaches to applied phenomenology and see which elements of these approaches might be adapted for our purposes.

\section{The challenges of observational research}

If one wants to use phenomenology in observational research, perhaps the most obvious field to turn to is anthropology, which has a well-established history of drawing inspiration from philosophical phenomenology when conducting observational studies (see, e.g., Csordas, 1990, 1999; Desjarlais, 1992; Desjarlais \& Throop, 2011). However, despite the extensive influence of phenomenology, anthropologists have provided little concrete methodological guidance on how to conduct phenomenological observations (certainly nothing that compares with the extensive methodological literature on phenomenological interviewing in fields like psychology and nursing). This is because anthropologists tend to use phenomenology as a broad theoretical background, rather than as a methodology. In this respect, anthropologists don't conduct "phenomenological observations" in a way that's analogous to how psychologists or nurse researchers might conduct "phenomenological interviews." If we want to find examples of a phenomenological approach to conducting observations, we'll therefore need to turn to fields that more commonly use phenomenology as a methodology.

In the field of nursing, we find at least one example of a phenomenological approach to observational research in the work of Karin Dahlberg, one of the 
progenitors of Reflective Lifeworld Research. As we explain in more detail in the following section, our aims differ in important respects from those of Dahlberg and her collaborators. Nevertheless, the problems that she outlines provide a useful frame for discussing the challenges of our approach and the solutions that we have developed.

Dahlberg identifies two major problems for phenomenological observational research. The first arises from the "surplus of meaning" (Dahlberg, 2006, 5) in human behavior. When we perceive another person, we perceive an expressive body that immediately conveys emotions, desires, and intentions through its gestures, facial expressions, and other bodily movements. The expressiveness of human behavior allows us to understand others both in everyday life and in the context of research in the human sciences. But, as Dahlberg says, when we investigate the other's behavior, we always find that "there are many more intentional objects than the phenomenon" (Dahlberg, 2006, 4). In other words, we never experience the phenomenon that we're investigating in isolation. It's always embedded in a broader context that we can't help but attend to. On the one hand, by attending to this broader context, we may discover phenomena that we hadn't anticipated. On the other hand, the sheer range of phenomena to consider can be overwhelming, causing the researcher to lose focus. This problem is not exclusive to observational research. It's possible, for example, for an interviewee to go off on tangents, providing information that is unrelated to the research question. But, when conducting an interview, the researcher may bring the participant back from a tangential remark and refocus them on the phenomenon of interest. When conducting an observational study, in contrast, the researcher is often not in a position to bring the participant back to the phenomenon of interest. Depending on the kind of observational study, they may not be able to actively engage the participant at all.

The second problem with observational research arises from the interpretation of expressive behavior. Observations, in contrast with traditional interviews, require that the researcher is the first one to formulate the participant's experience-as Dahlberg says, "it is the researcher who words the experience" (Dahlberg, 2006, 4). In an interview, the participant has the opportunity to present an initial interpretation of their experience, putting it in their own words and, thus, heading off or correcting the researcher's potential misunderstandings. The researcher will, of course, interpret interview data in subsequent analyses; but the range of legitimate interpretations is already constrained by how the participant described their own experience. In observational research, by contrast, the participant's behavior is open to a broader range of interpretations because the meaning of non-verbal expressions are often not as definite as the meaning of verbal expressions.

In light of these problems, one might assume that Dahlberg urges phenomenologists to stick to interviews and avoid observational research. But this is hardly the case. Rather, she says, "The emphasis on the surplus of meanings and the linguistic aspects of participative research points to the necessity of 'bridling' the evolving understanding, so that meanings do not come too carelessly or glibly, so that we do not make definite what is indefinite" (Dahlberg, 2006, 6). In her article, Dahlberg doesn't expand on her notion of bridling in detail. However, she articulates this approach more fully in her collaborative work with Helena Dahlberg and 
Maria Nyström (2008). Bridling is a way of keeping the researcher's pre-understanding in check. Pre-understanding encompasses the prejudices or presuppositions that the researcher has about the phenomenon being investigated. Our everyday ways of talking about and making sense of things shape how we understand the phenomenon that we're interested in. And our philosophical and scientific knowledge of the topic provides us with theoretical frames that we may not be fully aware of. Bridling, in short, is an open attitude toward the phenomenon being investigated, a commitment to not settle on an interpretation too quickly in light of one's prior theoretical frames and biases: "Following the principle of not making definite what is indefinite means allowing the phenomenon its indefiniteness for as long as possible" (Dalhberg et al., $2008,133)$. When applied to observational research, bridling helps address the two challenges outlined above: It requires that one acknowledge the ambiguities inherent in bodily expression and not be too quick to settle on a definite interpretation of the participant's experience.

We largely agree with these ideas. However, we diverge at a key point. Dahlberg and her collaborations say that bridling "is by no means something that could be understood as a methodological technique" $(2008,133)$. It is, instead, a phenomenological attitude or orientation toward the phenomena. We've found, however, that to understand the kinds of conditions that we're interested in, we need a way to focus or frame our study so that we can attend to a specific aspect of the condition and explore it in considerable depth. ${ }^{2}$ We outline this approach in the following section. At first, our approach may seem opposed to Dahlberg's recommendation of openness. However, as we make clear, our approach should be understood as operating within an attitude of "bounded openness." The researcher must still be open to novel discoveries and even to perspectives that they had not yet considered. But, to obtain the kind of depth and nuance required to understand complex experiences, including the experience of complex illness, the researcher needs to constrain the scope of her study in advance of conducting observations and interpreting data.

\footnotetext{
${ }^{2}$ Dahlberg's interest in observational research typically focuses on interactions among healthcare workers and patients. She refers, for example, to an observational study by Wireklint Sundström that found that the "smooth, often wordless, co-working between ambulance carers was of extreme importance" (as described in Dahlberg, 2006); yet, despite the importance of this kind of interaction, the ambulance workers did not mention it in their interviews. This shows that observations can often reveal aspects of experience that participants are not reflectively aware of. However, in this case, the ambulance workers could have, at least in principle, been reflectively aware of this aspect of their professional practice-perhaps if one asked different questions or interviewed different ambulance workers, such insights would have been articulated. Our own interest, by contrast, is primarily concerned with cases where the very capacities to reflect upon or report one's experience are compromised in illness or injury. In such cases, observational research becomes all the more important because it may be the only genuine mode of access to at least some aspects of the patient's experience.
} 


\section{Conceptual grounding in observational research}

How should we overcome the challenges of conducting observational phenomenological research? Here, we outline a conceptual approach to observational studies, building upon recent work on the use of phenomenological concepts, rather than phenomenological methods, in qualitative research (Fernandez, 2017; Fernandez \& Køster, 2019; Køster \& Fernandez, 2021, Zahavi \& Martiny, 2019; Zahavi, 2019). This approach draws inspiration from phenomenology's successful applications in psychiatry and the cognitive sciences, which rely on phenomenological concepts to guide their investigations. Dan Zahavi, for instance, has urged qualitative researchers to model their approach on these successful applications by drawing upon phenomenology's theoretical and conceptual frameworks, rather than phenomenology's philosophical methods, such as the epoché or reductions. Speaking of qualitative interviewing, he writes,

... it is all about conducting the interview in light of quite specific ideas and notions, notions taken from phenomenological theory. To conduct a phenomenological interview is consequently not simply a question of being open-minded and interested in first-person experience. It is very much also about adopting and employing a comprehensive theoretical framework that will allow one to ask the right questions. (Zahavi, 2019, 6)

This call for theoretical framing in qualitative research may seem to contrast with the position advanced by Dahlberg, Dahlberg, and Nyström. They say, "Preunderstanding may [...] include one's favorite theories or thought models which become part of, or worse yet, the starting point for the research. Research that blindly follows a theory or a thought model is not open" (2008, 134). However, the contrast may not be as strong as it at first seems. Zahavi does not, for instance, argue that we should take on phenomenology's theoretical frameworks dogmatically or unreflectively. In fact, the primary reason to take on phenomenology's theoretical frameworks is precisely because they allow the researcher to think outside dominant or competing theoretical frameworks.

What are these phenomenological frameworks that psychiatrists and cognitive scientists draw upon? They consist primarily of what phenomenologists call essential, ontological, or existential structures. As Zahavi writes, the task of phenomenology is to "...disclose, disentangle, explicate, and articulate those components and structures that are implicitly contained in the pre-reflective experience" $(2019,904)$. For our purposes, we'll follow Heidegger and simply refer to these structures as "existentials." These include selfhood, temporality, affectivity, and embodiment, among a range of other key structural features of human existence. When we apply these concepts in our own approach, we understand them as windows or lenses that provide us with a definite perspective on the phenomenon of interest. Which phenomenon we're interested in, and which questions we have about it, will determine which existentials should ground our study. We won't go into considerable detail on how to select existentials here as this has been addressed elsewhere (see Køster \& Fernandez, 2021) . 
Approaching a new phenomenon with a definite theoretical or conceptual framework may seem to undermine any possibility of openness or bridling, which are especially important in observational studies. However, we argue that a researcher can use this kind of framework to ground a phenomenological study while also remaining open in a way that's consistent with Dahlberg's approach to bridling. Consider, for instance, how phenomenological psychopathologists have approached the study of schizophrenia. These researchers have extensive knowledge of the condition, which they've gained through medical training, their own research, and interactions with patients. When they turned to phenomenology to study this condition, they didn't put this prior knowledge to the side so that they could view the phenomenon in a completely unbiased light. Rather, they drew on key phenomenological concepts that, in light of their prior knowledge, they thought might be valuable for understanding schizophrenic experience. In particular, they focused on the concept of selfhood. By drawing upon phenomenology's distinctions among different kinds and levels of selfhood (e.g., the distinction between minimal selfhood and narrative selfhood), they were able to formulate pointed questions that helped them identify some of the core disturbances characteristic of schizophrenic experience. This kind of research has proved a valuable resource for both the understanding and diagnosis of schizophrenia (Parnas et al., 2005, 2013).

But doesn't this way of conducting phenomenological research limit our potential understanding of the condition in question? Aren't there features of schizophrenia that the researchers may have missed by focusing too narrowly on the structure of selfhood? It's certainly possible to miss out on key features of a condition within the scope of a single study. But we need to keep in mind that our understanding of complex experiences must be developed through an ongoing and expanding research program. Each individual study can only take so many perspectives upon the phenomenon if it's going to explore these aspects with the depth and nuance required. A study that inquires into the experience of schizophrenia, broadly construed, can only scratch the surface of this condition. A study that, in contrast, focuses specifically on an existential structure, such as selfhood, temporality, or embodiment, allows the researcher to explore this aspect of experiential life in considerably greater depth.

This conceptually grounded approach is consistent with calls for bridling for two reasons. First, we need to think of these studies as just one small piece of an overarching research program. Each existential structure provides a window onto the phenomenon in question and allows the researcher to attend to this aspect of the phenomenon. In the case of complex illness experience, there's always the risk that the particular existential structure that the researcher selected will not provide much insight into the condition. The researcher might investigate, for instance, the affective alterations associated with a particular condition, only to discover that the condition isn't characterized by an affective disturbance. The possibility of running into dead ends may suggest that the particular study is too narrow. But if we understand openness as an attitude that belongs to the research program as a whole, then we should understand this individual study as closing off a particular path so that we can direct our attention to more valuable research questions.

Second, and following from the first, a study may point the researcher toward other existential structures that they had not intended to explore and had not realized 
were central to understanding the condition in question. To provide an analogy, this is like peering into a room through a window, only to see another window on the other side of the room that may provide a better vantage point. We'll illustrate this kind of development in Sect. 7, where we show how a study of neglect that was initially framed through the concepts of body schema and body image revealed that the condition should be explored, in future studies, through the concepts of agency and ownership.

Up to this point, our discussion has remained fairly theoretical and abstract. To clarify our approach in a more concrete way, we turn to hemispatial neglect and elaborate our approach in the following sections.

\section{A case study of neglect}

Before discussing how a qualitative study of neglect was developed and implemented, we first present an account of a patient with neglect, which is a composite of patients that one of the authors has interacted with in her research and practice. The case study serves multiple functions in the context of this article. It introduces the reader to the condition of neglect. It highlights some of the challenges involved in understanding the experience of living with this condition. And it also illustrates that qualitative researchers seldom enter their research projects as blank slates. Rather, as we discuss in more detail in Sect. 7, researchers should draw upon previous clinical and research experience when determining the optimal conceptual grounding of their research project.

Consider the following case: Liza, a lawyer in her early sixties, was admitted to the acute stroke unit yesterday. During doctors' rounds, Liza was asked to describe what had happened at home and why she had been admitted to the hospital. She explained correctly that she had suffered a stroke. But she said that she had not initially noticed that anything was wrong. She had just gone to the bathroom to take a painkiller because she had a headache. While walking back to bed, she tripped over her grandchild's toys and fell to the floor. She just wanted to rest for a while. But her husband insisted that she should go to the hospital. Liza was quite upset with her husband because his concerns didn't make any sense. As far as she was concerned at that point, she was just fine.

Liza's apparently coherent account of how she ended up in the hospital conflicted with her husband's description of what happened. He was quite concerned that his usually very sensible wife was ignorant of the fact that she could not move her left side and puzzled by her peculiar statements and actions. He explained that Liza had stood up to take a pain killer for her headache. Shortly after, he heard coughing and gasping from the bathroom, so he rushed to see what was wrong. Liza was standing in front of the mirror trying to swallow her pain medication, with water leaking out of her mouth. He guided her into their bedroom. But, before they reached their bed, Liza lost all strength in the left side of her body and fell. According to her husband, Liza provided "bizarre explanations" to account for why she could not stand up and kept insisting that she had fallen over their grandchild's toys, even though there were no toys on the floor. The strange behavior continued after hospital admission. 
While fully awake, alert, and able to carry on a seemingly normal conversation, Liza behaved quite strangely, became annoyed with the staff, and had difficulties comprehending why they prohibited her from walking independently. She did not fully acknowledge that she was paralyzed. For example, if she was asked to move her left arm, she elevated her right arm instead and was quite satisfied with her own performance, expressing the belief that she had successfully moved her left paralyzed arm. Liza's physical attempts to move as she did prior to the stroke would cause her to, for instance, tumble back when trying to sit up. On several occasions, she accused staff of holding her down or having her constrained her to the bed. This "rough treatment" affected her deeply and her frustration was almost tangible. She said, "I'm a prisoner, nobody listens to reason. I just get a rude answer when I ask them (the staff) to lower the bed rails, even if I ask nicely."

Three weeks after the stroke, Liza became more aware that her left-sided extremities were indeed paralyzed. Nevertheless, she frequently attempted to ambulate by herself-even though she had promised, quite convincingly, to call for assistance if she needed to move. She appeared forgetful about her left-sided paralysis when acting impulsively, such as when she suddenly needed to go to the bathroom, wanted to fetch her phone on the table, or was thirsty. At one moment she could engage in serious conversations where she expressed, for instance, concern over never being able to manage at home again due to her disability. Moments later, she might ask her relatives to bring her the needlework and embroidery that she was working on at home so she could finish it, which she obviously was not capable of working on due to her paralysis.

Liza had suffered from a heterogeneous condition called neglect. In the most severe cases of neglect, patients may display quite dramatic behavior, acting as if the left side of their environment has completely ceased to exist (Bartolomeo, 2014). In less severe cases, patients only occasionally miss out on left sided stimuli. Characteristic examples of neglect behavior include seeing patients collide with objects or people to the left, situations where they act ignorant of the left side of their body, and lack awareness of the extent of their own disability (anosognosia) (Bonato et al., 2012; Ronchi, 2011). However, it may also involve situations in which patients transpose events from the left hemispace onto the right (allesthesia) or a tendency for patients to fabricate stories or otherwise venture to justify the missing details in their experiences (Bottini et al., 2009). Patients may also complain about diversion and unfamiliarity of the left side of their body or maintain that their affected limbs belong to the therapist, physician, or nurse. Such confabulations take place without intentional dishonesty and they are not a sign of mental disorder (Bottini et al., 2009; Rode et al., 2014). When these errors of perception are "simple", they can be corrected easily by pointing them out to patients. However, in more complex cases, patients persistently overthrow any attempts at rectification and act threatened if they are confronted with their mistaken perceptions (Feinberg et al., 2005).

At first glance, patients with neglect appear articulate and may seem to have the cognitive abilities required to process and provide first-person, self-reflective reports. It is thus tempting to merely interview patients with neglect if you wish to gain insight into their experiences. However, in spite of their verbal abilities, they are not "good informants" in the traditional sense; no matter how skilled an 
interviewer might be, the interviewee with neglect simply cannot provide the kind of evidence that such a study requires. The responses of patients with neglect may not be sufficiently anchored in reality and there is characteristically a mismatch between their perspectives of a given situation and the perspectives of others. Observations are thus of pivotal importance.

\section{Approaches to observational research}

Now that we have a basic understanding of neglect and why it needs to be studied through observation, we should outline the various kinds of observations that a researcher might conduct:

- Observing in proximity with direct interaction: On this approach, the researcher enacts along with participants, which provides opportunities to determine how they perceive and how they tune in to their daily activities. The researcher is with the participants, not just beside them in the pursuit of understanding the experience. Being with participants and having some degree of joint intentionality requires reciprocity between the participant's and researcher's intentions and acts. Actions are interlocked and, to some degree, synchronized and recalibrated in the immediacy of interactions (Schutz, 1967). ${ }^{3}$

- Observing during highlighted events: These are situations where the researcher pays attention to how participants engage with others, for instance by accompanying them to a rehabilitation session or observing them while they watch television. In these situations, the researcher is not burdened with the necessity to act but takes a more unobtrusive stance in observing a scene.

- Reports of observations from others: In the case of illness experience, this may include reports from friends, relatives, or hospital staff. This is the least reliable form for observation but may still provide important information that furnishes future targets for the researcher's own observations.

Observations, as must be emphasized, are not used to reduce patients' experiences to their actions. From a phenomenological standpoint, observation exceeds the insight that one could gain from an objectifying third-person perspective. Rather, through observation, one attends to the bodily expressions of a person's subjective experience, including his desires, intentions, or emotions. And, because phenomenological observations gear into the subjective life of the participant, they also call for methods that allow the researcher to integrate observations and self-reflective reports to gain a more complete understanding of the participant's experience.

\footnotetext{
3 Schutz argues that although observation of the other is indirect, it still, in some cases, provides better access to the other's experience than I might even have to my own experience. Through observations I can directly observe the other's subjective experience in the midst of their actual occurrence which is something that is impossible for my own experiences: "we have to wait for our own [experiences] to elapse in order to peer at them as they recede into the past. No man can see himself in action, any more than he can know the "style" of his own personality" (Schutz, 1967, xxvi).
} 
The way that observations and interviews supplement each other in the data collection of complex illness experiences is illustrated clearly when Liza claims that other people are constraining her ability to move freely, for example when she wants to stand up. This makes her feel trapped, misunderstood, and even maltreated. On the contrary, the researcher observing Liza knows for certain that other people are not constraining her movements. The difference between the interpretations that Liza and the researcher entertain does not mean that their experiences are not about the same thing. Their experiences have common ground that should be joined to provide a coherent report of Liza's subjective experience. We are, however, not looking for perfect attunement between these perspectives. On the contrary, the desynchronized perspectives may be precisely what reveals the core of her complex illness experience.

For patients such as Liza, who are prone to incorporate fictional elements into their stories, it may be extremely difficult for the researcher to discern what is true or what is not. However, the experience that the patient talks about does not have to be "true" and the researcher does not have to agree with the patient's perspective for the experience to provide essential information for understanding their condition. There is a sense in which patients' experiences of "what it is like" and their self-reflections are by nature "epistemically secure (that is self-intimating, infallible, indubitable and incorrigible) but also metaphysically and epistemically direct" (Choifer, 2018, 336). But there's also a sense in which first-person beliefs can be meaningfully "corrected by others or be overridden by external evidence" (Zahavi, 2005, 13)—or, as we prefer to look at it, not overridden but rather merged.

In the case of Liza, it is obvious that the phenomenologist is faced with challenges that go beyond the ones described by Dahlberg (2006). Dahlberg seems to entertain the idea that data gathered by interviews are more "to the point" than data gathered through observation. But, as illustrated, Liza's self-reflective knowledge cannot be interpreted correctly without paying attention to her actions. In fact, there's a sense in which her bodily actions are more "honest" than her verbal account.

Having provided some practical guidance on different forms of observations, we now turn to an empirical study of neglect to illustrate how observational research, coupled with limited interviews, can be framed by phenomenological concepts in order to focus on specific features of experience.

\section{An example of conceptual grounding in an observational study of neglect}

It is clear that neglect experience is remarkably complex. The condition includes more elements than we can possibly capture without using some kind of compass to navigate toward the cardinal features of the experience. Without such a guide, we run the risk of gaining too much irrelevant and superficial information. If the phenomenologist sets out with an overly broad research question-such as "What is the subjective experience of neglect?"- then they're unlikely to gain new insight into the experience. By using phenomenological concepts, the researcher can focus on a specific dimension of experience and study it in considerable detail. But how does 
the researcher select the most relevant concepts to ground a study? The researcher should draw upon prior knowledge of the topic, including scientific scholarship, first-person reports, memoirs of illness experience, clinical reports, and so on. By drawing on this body of knowledge, they should identify structural features of subjectivity that may be key to understanding the experience in question. Then, they should devise a research question and approach that focuses specifically on those features of experience and inquire into them in depth. ${ }^{4}$

For a concrete example of how such concepts can ground observational research, we will turn to one of the authors' empirical studies of neglect. Participants included 12 neglect hospital admitted patients ( 8 women) with moderate to severe neglect within 21 days following stroke (Klinke et al., 2015). Finding the most fruitful concepts to ground the data collection and analysis was a time-consuming and laborious endeavor. It was decided early on that the key focus would be on embodiment. However, to focus the study even further, an array of concepts related to bodily action and body awareness were explored by investigating their different uses within phenomenology and the cognitive sciences and by considering how they might relate to neglect. Previous clinical encounters with neglect patients were used as a springboard to consider if the concepts were likely to furnish new insights and to identify key events where observations of participants should take place. How the concepts could be used as tools to merge different types of data (i.e., interview and observational data) was also an important consideration. To make sure that the most illuminating concepts were selected, the research team, consisting of healthcare professionals and researchers specialized in neglect as well as philosophically trained phenomenologists, engaged in repeated discussions about the aspects of neglect that might be better understood through phenomenology and the concepts that would be most valuable to the study. ${ }^{5}$ Finally, three concepts- "body schema", "body image", and "affordance" - were selected because their conceptual distinctions seemed particularly valuable for understanding components of embodiment associated with neglect (Klinke et al., 2014).

In our previous experience with neglect patients, we had observed that they often acted as if they still had the same bodily capabilities as they did prior to the stroke, which implied an asymmetry between the body schema and body image. The body schema constitutes the tacit and habitual ways that the body, almost automatically, accomplishes daily tasks. To proficiently use the body to fulfill one's intentions requires a sense of proprioception, i.e., a tacit sense of bodily posture and position, and an advanced set of sensory-motor skills. Without paying conscious attention to movement, the body is acquainted to its own capabilities during the unperturbed

\footnotetext{
${ }^{4}$ For a more detailed account of how this process can be used in the design of interview-based studies, see (Køster \& Fernandez, 2021).

${ }^{5}$ It is important to use the resources of intersubjective collaboration. The researcher had extensive clinical experience with neglect patients that she could draw on but needed to collaborate with experts in phenomenology to help expand her conceptual understanding. A reverse situation is presented by Kristian Martiny in his study of Cerebral Palsy where he as a phenomenologist discussed his observations of research participants with neuro-physiological researchers and healthcare professionals to expand his clinical comprehension (Høffding \& Martiny, 2016).
} 
flow of daily activities and finetunes its movements according to the demands of the environment (Gallagher, 2005). The body image, in contrast, refers to a range of experiences, including emotions, beliefs, and perceptions that a person has about one's body (Gallagher, 2005).

Under normal circumstances, even after stroke, people are acquainted with their bodily capabilities. If, for instance, you suffered a pure motor paralysis and were relearning to use your fingers, you would be aware of your bodily limitations. When trying to grab a glass of water, you would concentrate intensely on closing your fingers around the glass while lifting it up to your mouth. You wouldn't simply attempt to reach out and grab the glass of water in the same way that you had before your paralysis. This is because your body schema has updated to accommodate your current bodily capacities. You then rely, in part, on your body image when you explicitly attend to the movements of your fingers and their position around the glass. This is, however, not how neglect patients behave when they have paralysis following a stroke. This kind of body-awareness and ability to adjust seems to have vanished and causes neglect patients to misperceive the kinds of actions that their environment affords. Affordances can crudely be characterized as the range of unique possibilities within the environment that an individual acts upon (Gibson, 1986). So, rather than experience an environment full of brute, meaningless objects, we experience our environment as filled with objects that afford various possibilities for action. For instance, a floor is walkable, an apple is eatable, a chair sittable, and so forth. However, a floor may no longer be walkable if you have left-sided paralysis. Nevertheless, we had noticed that patients with neglect tended to act as if the floor was still walkable because they misperceive such affordances. Affordances thus seemed to provide a way to describe situations where an asymmetry between body schema and body image emerges due to neglect. To capture situations where neglect patients misperceived what their environments afforded them and attempted to use bodily capacities that they no longer had, the study focused on the following main question: "What does it mean to misperceive affordances and how do misperceived affordances manifest in patients with neglect?".

When preparing for data collection, the concepts are "frontloaded", which means that they're integrated into the initial design of the study (Gallagher, 2003; for a more detailed account of how frontloading, which was originally developed as a way to integrate phenomenology and experimental cognitive science, can also be used in qualitative research, see Køster \& Fernandez, 2021). This helps the researcher frame the study and decide on the content of the data collection protocol, including guidance on what to ask and which situations to observe. ${ }^{6}$ For example, because we wanted to better understand affordances that neglect patients acted upon, we focused our observations on daily activities that required a certain kind of bodily awareness. Our observations were especially targeted to include daily care situations where

\footnotetext{
${ }^{6}$ Due to ethical requirements, the researcher will typically need a framework in advance, which provides detail about the character/intimacy of the observations and the corresponding questions that will be posed to participants. However, the framework should be flexible enough to be tailored to fit each participant's unique neglect manifestations.
} 
we knew from our clinical experience that mismatches between the body schema and body image were prone to occur. It encompassed both "online" actions, where patients responded to affordances in the immediacy of a situation without contemplating what they were about to do (e.g., when responding to a sudden need to go to the bathroom), as well as situations that required reflection on one's own bodily capabilities prior to action (e.g., when staff provided guidance or corrections on how to dress or ambulate). We deliberately used different modes of observation, enacting and observing interaction between neglect patients and others. ${ }^{7}$ By relying on our pre-selected set of concepts we were able to distinguish situations where patients misperceived affordances-for instance, when they acted surprised about the outcomes of their behavior or where there was a mismatch between their perspective of the situation and other peoples' perspective.

The data collection also included questions corresponding to the observations, for instance questions related to lack of insight. For example, when patients requested to be discharged or to ambulate without supervision, they were asked, "Do you know why you are in the hospital?" or "What happened in this situation and how have your bodily abilities changed?" And when relatives acted surprised and did not fulfill the patient's wishes, such as lowering their bedrails so they could get out of bed despite being paralyzed, patients were later asked, "How did you experience the way that other people responded to your wishes, for instance when you asked your wife to lower the bedrails so you could go to the bathroom by yourself?" This line of questioning was not executed to verify or falsify the participants' experiences, but rather to reveal the absence in their bodily awareness and how they behaved in light of this absence, both in actions and words-and also to establish if further observations, during other situations or when inquiring about the same events at different time-points, might bring more nuance to the data. ${ }^{8}$ Gathering data on the same "event", both in proximity of the event and later on, turned out to be important even in the preliminary analysis of data from the first participant: a 48 year old woman with moderate neglect who had slight paralysis in her left extremities. She could ambulate with minor physical support but was nevertheless dependent on constant supervision due to her neglect. An event where the patient neglected to remove her shirt from her left arm before showering played out as follows:

\footnotetext{
7 Observation took place through interaction or unobtrusively while others (e.g., relatives or medical staff) interacted with participants for four to eight hours, denoting actual hours of activity. To achieve this, the researcher observed each participant during 2-4 days at different time-points. The clinical observations were used to prompt in-situ interviews and guide the content of more formal interviews. Trust can be a confounding issue during data collection because patients typically refrain from volunteering sensitive, personal details or acting naturally if a trusting relationship between them and the researcher is not established. Therefore, it is essential to establish a rapport that invites patients to express their experiences, however odd or uncanny. To establish such a rapport, the researcher will need to demonstrate genuine interest and appear knowledgeable when patients convey their experiences.

${ }^{8}$ Rather than have a generic list of observations and questions, the researcher builds a framework that allows for flexibility to interrogate different contexts of misperceived affordances, see Klinke et al., 2014, 2015, for examples of this kind of framework.
} 
Initially when her attention was drawn to the soaked clothes, she showed comprehension: "I do not seem to be in control of anything hanging onto here [pointing at her left arm]." This insight, however, quickly tapered off to a point where she minimized the difficulties profoundly. When requested to describe how she had managed to shower later the same day, the prompt reply was "fine-this was no problem." When confronted with the soaked clothes, she confirmed that "a small amount of water accidently squirted onto here [pointing to her left arm]; this happens all the time." Any additional pursuing was not possible because she became upset when her performance was questioned. (Klinke et al., 2015, 1629)

Pursuing specific events of misperceived affordances in the remaining 11 study participants revealed that memories of events occurring on their left side, including verbal information provided within the neglected space, often faded over time or were replaced by confabulations. In a similar manner, other distinctive features of neglect emerged throughout the study when the researcher interrogated misperceived affordances. The showering example also shows how it was impossible to disentangle interviews and observations completely. Thus, patients were asked questions at the moment the researcher observed neglect. Their reflective responses to these questions - or their lack of capacity to acknowledge their neglect behaviorfurnished new ideas for observations. This worked in a circular manner, where the researcher continually moved closer to the "heart" of the experience while accommodating the observations to suit each patient's unique neglect problems.

The process of frontloading concepts to frame a phenomenological study can be characterized as explorative and dynamic. In fact, looking through one conceptual window sometimes led to the discovery of conceptual windows that we had not previously considered, but provided new opportunities for observation and ways of posing questions. For instance, when studying body schema, body image, and affordances in neglect, we also realized that studying various aspects of "agency" and "ownership" would be valuable for a follow-up study. When conducting a study framed through the concepts of agency and ownership, observations would center on situations that display lack of bodily control and problems in feeling the body as mine. Moreover, subsequent interviews may include general questions, such as "Do you feel that you have control over your body/situation?" as well as questions about specific events, such as "Can you describe how you used your arms when you were getting dressed this morning?" By conceiving of each concept as a window onto the phenomenon, we understand that other windows may offer valuable insight into the experience-and these insights are not fragmentary, since each provides a perspective on the same phenomenon. Investigating complex illness is akin to mapping unplotted territory. You learn more along the way and the data collection continuously evolves:

[The] ability to observe increases with increasing knowledge (or decreases when it learns that it was mistaken in some piece of background information it employed). In the process of acquiring knowledge, we not only learn about nature, we also learn how to learn about it, by learning (among other things) what constitutes information and how to obtain it. (Shapere, 1982, 513-514). 
By having researched neglect patients' experiences in light of their body schema, body image, and affordances, it became clear that their habitual bodily skills in many situations no longer align with actual bodily skills - and this loss of alignment is largely outside the scope of their reflective self-awareness, as illustrated by how they misperceive possibilities in the environment. Merleau-Ponty describes similar quandaries in a patient with a phantom limb when he writes,

At the same moment that my usual world gives rise to habitual intentions in me, I can no longer actually unite with it if I have lost a limb. Manipulable objects, precisely insofar as they appear as manipulable, appeal to a hand that I no longer have.... The patient knows his disability precisely insofar as he is ignorant of it, and he ignores it precisely insofar as he knows it...: it is as though our body comprises two distinct layers, that of the habitual body and that of the actual body. (Merleau-Ponty, 2012, 84)

In contrast to patients with phantom limbs, patients with moderate to severe neglect have difficulties upgrading their body schema according to their actual capabilities. They continue to misperceive affordances and not learn from their mistakes. ${ }^{9}$

By frontloading key concepts, we were better able to attend to important issues associated with the embodied subjective experience of neglect and untangle its existential impact from other disorders. It's important to note that while we expect that many aspects of our approach will apply broadly to the study of other complex experiences, including those characteristic of some neurological and psychiatric disorders, it will need to be modified for individual research projects.

\section{Conclusion}

Researchers using applied phenomenology to study complex illness and other experiential alterations should make use of the rich resources one can find in phenomenology's philosophical tradition. These resources include a vast number of concepts that can structure a study without predetermining the study's conclusions, thereby maintaining an attitude of bounded openness. Frontloading concepts allows the researcher to focus on a particular aspect of experience and study it in considerable detail. And this process can be used to more tightly integrate philosophical phenomenology with observational research methods.

People with neglect, and other complex illness experiences, are often incapable of providing coherent reflections of their experiences. Therefore, they are often excluded from qualitative research studies, including approaches that use applied phenomenology. Yet, experiences such as theirs are perhaps the most important cases for us to study, since they are often poorly understood by healthcare professionals. To properly understand these experiences, the researcher needs multiple modes of access to the participant's subjectivity, including through interviews and

\footnotetext{
${ }^{9}$ For examples of changes that specifically pertains the body schema, body image, and affordances in neglect, see Klinke et al., 2014.
} 
observations. Such studies have the potential to inform and guide clinical care, insofar as they provide clinicians with more insight into the experiences and perspectives of their patients. And there are doubtless many other kinds of experiences and experiential alterations that might be better understood by using a phenomenological approach to observational research.

The practice of observational research within applied phenomenology may be deemed unconventional, since philosophical phenomenology is often characterized as a first-person reflective method. However, as we've argued, many of the classical phenomenologists used observations in their own research, including in the study of complex illness experience. And observational methods are not entirely absent from contemporary approaches to phenomenological qualitative research-although genuine integrations of phenomenology and observational methods have been rare. Self-reflective reports and observations of behavior should not be understood as standing in opposition. Rather the researcher can draw on key concepts within phenomenology to integrate these two perspectives and gain greater insight into the structures of the participant's subjectivity and their experience.

Author contributions Both authors contributed equally to the idea of the article and its drafting.

\section{Declarations}

Conflicts of interest The authors have no conflicts of interest to declare that are relevant to the contents of this article.

Open Access This article is licensed under a Creative Commons Attribution 4.0 International License, which permits use, sharing, adaptation, distribution and reproduction in any medium or format, as long as you give appropriate credit to the original author(s) and the source, provide a link to the Creative Commons licence, and indicate if changes were made. The images or other third party material in this article are included in the article's Creative Commons licence, unless indicated otherwise in a credit line to the material. If material is not included in the article's Creative Commons licence and your intended use is not permitted by statutory regulation or exceeds the permitted use, you will need to obtain permission directly from the copyright holder. To view a copy of this licence, visit http://creativecommons.org/licen ses/by/4.0/.

\section{References}

Bartolomeo, P. (2014). Attention disorders after right brain damage. Springer.

Bonato, M., Priftis, K., Marenzi, R., Umiltà, C., \& Zorzi, M. (2012). Deficits of contralesional awareness: A case study on what paper-and-pencil tests neglect. Neuropsychologia, 26(1), 20-36.

Bottini, G., Sedda, A., Ferre, E. R., Invernizzi, P., Gandola, M., \& Paulesu, E. (2009). Productive symptoms in right brain damage. Current Opinion in Neurology, 22(6), 589-593.

Choifer, A. (2018). A new understanding of the first-person and third-person perspectives. Philosophical Papers, 47(3), 333-371.

Cole, J. (1995). Pride and a daily marathon. MIT Press, Gerald Duckworth \& Co., Ltd.

Csordas, T. J. (1990). Embodiment as a paradigm for anthropology. Ethos, 22(1), 5-47.

Csordas, T. J. (1999). The body's career in anthropology. In H. L. Moore (Ed.), Anthropological Theory Today (pp. 172-205). Polity Press. 
Dahlberg, K. (2006). The individual in the world-the world in the individual: Towards a human science phenomenology that includes the social world. Indo-Pacific Journal of Phenomenology. https://doi. org/10.1080/20797222.2006.11433932

Dalhberg, K., Dalhberg, H., \& Nyström, M. (2008). Reflective lifeworld research (2nd ed.). Studentlitteratur.

Desjarlais, R. (1992). Body and emotion: The aesthetics of illness and healing in the Nepal Himalayas. University of Pennsylvania Press.

Desjarlais, R., \& Throop, C. J. (2011). Phenomenological approaches in anthropology. Annual Review of Anthropology, 40, 87-102.

Englander, M. (2012). The interview: data collection in descriptive phenomenological human scientific research. Journal of Phenomenological Psychology, 43(1), 13-35.

Englander, M. (2020). Phenomenological psychological interviewing. The Humanistic Psychologist, $48(1), 54-73$

Feinberg, T. E., Deluca, J., Giacino, J. T., Roane, D. M., \& Solms, M. (2005). Right-hemisphere pathology and the self: Delusional misidentification and reduplication. In T. Feinberg \& J. P. Keegan (Eds.), The lost self: Pathologies of the brain and identity (pp. 100-130). Oxford University Press.

Fernandez, A. V., \& Køster, A. (2019). On the subject matter of phenomenological psychopathology. In The Oxford handbook of phenomenological psychopathology Edited by G. Stanghellini, M. Broome, A. V. Fernandez, P. Fusar-Poli, A. Raballo, and R. Rosfort (pp. 191-204). Oxford University Press.

Fernandez, VA. (2017). The subject matter of phenomenological research: existentials modes and prejudices. Synthese, 194(9), 3543-3562. https://doi.org/10.1007/s11229-016-1106-0.

Gallagher, S. (2003). Phenomenology and experimental design toward a phenomenologically enlightened experimental science. Journal of Consciousness Studies, 10(9-10), 85-99.

Gallagher, S. (2005). How the body shapes the mind. Oxford University Press.

Gibson, J. J. (1986). The ecological approach to visual perception. Psychology Press, Taylor \& Francis Group.

Giorgi, A. (2009). The Descriptive Phenomenological Method in Psychology: A Modified Husserlian Approach. Duquesne University Press.

Høffding, S., \& Martiny, K. (2016). Framing a phenomenological interview: What, why and how. Phenomenology and the Cognitive Sciences, 15(4), 539-564.

Klinke, M. E., Thorsteinsson, B., Jónsdóttir, H. (2014). Advancing Phenomenological Research. Qualitative Health Research, 24(6), 824-836. https://doi.org/10.1177/1049732314533425.

Klinke, M. E., Zahavi, D., Hjaltason, H., Thorsteinsson B., Jónsdóttir H. (2015). Getting the Left Right. Qualitative Health Research, 25(12), 1623-1636. https://doi.org/10.1177/1049732314 566328.

Køster, A., Fernandez, A. V. (2021) Investigating modes of being in the world: an introduction to Phenomenologically grounded qualitative research. Phenomenology and the Cognitive Sciences. https://doi.org/10.1007/s11097-020-09723-w

Merleau-Ponty, M. (1964). "Phenomenology and the Sciences of Man." In The Primacy of Perception, translated by John Wild (43-95). Northwestern University Press.

Merleau-Ponty, M. (2012). Phenomenology of perception (D. A. Landes, Trans.). Routledge. (Original work published 1945).

Parnas, J., Møller, P., Kircher, T., Thalbitzer, J., Jansson, L., Handest, P., \& Zahavi, D. (2005). EASE: Examination of anomalous self-experience. Psychopathology, 38(5), 236-258.

Parnas, J., Sass, L. A., \& Zahavi, D. (2013). Rediscovering psychopathology: The epistemology and phenomenology of the psychiatric object. Schizophrenia Bulletin, 39(2), 270-277.

Rode, G., Ronchi, R., Revol, P., Rossetti, Y., Jacquin-Courtois, S., Rossi, I., et al. (2014). Hyperschematia after right brain damage: A meaningful entity? Frontiers in Human Neuroscience. https://doi.org/10.3389/fnhum.2014.00008

Ronchi, R. (2011). Behavioral monitoring disorders in unilateral spatial neglect: Productive symptoms and impaired awareness of disease (Doctoral dissertation, Università degli Studi di Milano-Bicocca). https://boa.unimib.it/retrieve/handle/10281/19801/25185/PhD_unimib_ 042932.pdf Accessed 19 October 2020.

Sass, L., \& Pienkos, E. (2013). Varieties of self-experience: A comparative phenomenology of Melancholia, Mania, and Schizophrenia, Part I. Journal of Consciousness Studies, 20(7-8), 103-130.

Schutz, A. (1967). The phenomenology of the social world (G. Walsh, F. Lehnert, Trans.). Northwest University Press. (Original work published in 1932) 
Shapere, D. (1982). The concept of observation in science and philosophy. Philosophy of Science, 49(4), 485-525.

Smith, D. W. (2018). Phenomenology, In E.N Zalta (Ed.), The Stanford Encyclopedia of Philosophy (Summer 2018 edition), https://plato.stanford.edu/archives/sum2018/entries/phenomenology/ Accessed 19 October 2020.

Smith, J. A., Flowers, P., \& Larkin, M. (2009). Interpretative Phenomenological Analysis: Theory. Sage.

van Manen, M. (1990). Researching Lived Experience: Human Science for an Action Sensitive Pedagogy. Althouse Press.

van Manen, M. (2016). Phenomenology of Practice: Meaning-Giving Methods in Phenomenological Research and Writing. Routledge.

Varela, F. (1996). Neurophenomenology: A methodological remedy to the hard problem. Journal of Consciousness Studies, 3(4), 330-349.

Varela, F. J., Shear, J. (Eds.). (1999). The view from within: First-person approaches to the study of consciousness. Imprint Academic.

Zahavi, D. (2005). Subjectivity and selfhood: Investigating the first-person perspective. MIT Press.

Zahavi, D. (2019). Getting it quite wrong: Van Manen and Smith on phenomenology. Qualitative Health Research, 29(6), 900-907.

Zahavi, D., \& Martiny, K. M. (2019). Phenomenology in nursing studies: New perspectives. International Journal of Nursing Studies, 93, 155-162.

Publisher's note Springer Nature remains neutral with regard to jurisdictional claims in published maps and institutional affiliations. 